\title{
NASATM- \\ PASSIVELY ADAPTIVE INFLATABLE STRUCTURE FOR THE SHOOTING STAR EXPERIMENT
}

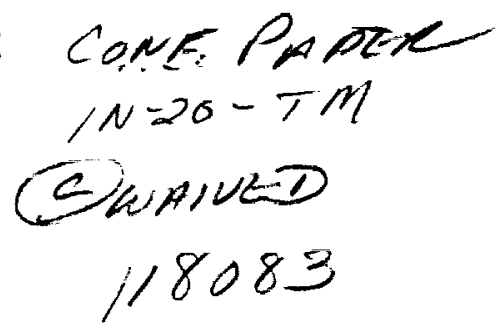

\author{
Michael L. Tinker * \\ Structural Dynamics and Loads Branch/ED23 \\ Structures and Dynamics Laboratory \\ NASA/Marshall Space Flight Center \\ Huntsville, AL 35812
}

\begin{abstract}
An inflatable structural system is described for the Shooting Star Experiment that is a technology demonstrator flight for solar thermal propulsion. The inflatable structure is a pressurized assembly used in orbit to support a fresnel lens for focusing sunlight into a thermal storage engine. When the engine temperature reaches a preset level, the propellant is injected into the storage engine, absorbs heat from a heat exchanger, and is expanded through the nozzle to produce thrust. The inflatable structure is an adaptive system in that a regulator and relief valve are utilized to maintain pressure within design limits during the full range of orbital conditions. Further, the polyimide film material used for construction of the inflatable is highly nonlinear, with modulus varying as a function of frequency, temperature, and level of excitation. A series of tests is described for characterizing the structure in response to various operating conditions.
\end{abstract}

\section{Introduction}

The Shooting Star Experiment (SSE) is a Space Shuttle payload and technology demonstrator flight for solar thermal propulsion. The basic concept behind solar thermal propulsion is to utilize sunlight or solar energy as a means of heating a working fluid (propellant) to provide thrust at increased specific impulse. As described in Ref. 1, thrust is produced by expanding the heated propellant through a nozzle. No combustion occurs, and the thrust level is low. For this reason, solar thermal propulsive systems are mainly applicable for orbital transfer vehicles.

The SSE is a precursor mission to the Solar Thermal Upper Stage (STUS), which is described in Ref. 2. The engine system for the STUS is designed to utilize hydrogen propellant to produce a thrust level of about $2 \mathrm{lbf}$. Two parabolic collectors will be used that can be rotated and gymballed for focusing sunlight into an absorber cavity

\section{*Aerospace Technologist, Structural Dynamics; Senior Member AIAA}

Copyright $\Theta 1998$ by the American Institute of Aeronautics and Astronautics, Inc. No copyright is asserted in the United States under Title 17, U.S. Code. The U.S. government has a royalty-free license to exercise all rights under the copyright claimed herein for Governmental purposes. All other rights are reserved by the copyright owner.
(Fig. 1, from Ref. 3). The collectors will be inflated after separation of the upper stage from the launch vehicle.

The Shooting Star Experiment will demonstrate the basic technologies required for the STUS, but will be on a smaller scale. Critical technologies being developed or advanced for the SSE include not only the inflatable structure constructed of polyimide thin-film material, but also the polyimide lens, the thermal storage engine constructed of solid rhenium and rigidized rhenium foam, and a centering/pointing system. The focus of this paper is to (1) describe the inflatable and its subsystems, (2) discuss a series of tests for characterizing the structure and the nonlinear polyimide film material, and (3) describe structural modeling of the inflatable based on test results.

\section{Description of the Shooting Star Experiment and its Inflatable Structure}

A major advantage of using inflatable structures in space is their extremely light weight. This makes inflatables a perfect match for solar thermal propulsion because of the low thrust levels available. An obvious second advantage is on-orbit deployability and subsequent space savings in the launch configuration. A recent technology demonstrator flight for inflatable structures was the Inflatable Antenna Experiment (IAE) that was deployed on orbit from the Shuttle Orbiter. Although difficulty was encountered in the inflation/deployment phase, the flight was successful overall and provided valuable experience in the use of such structures (Ref. 4).

As shown in Fig. 2, the SSE will be carried on a Spartan spacecraft and launched in the Space Shuttle. An instrument canister will house the thermal storage engine and a secondary solar concentrator, and a special container will be used for storing the inflatable during launch. On orbit, the Spartan spacecraft and the SSE will be deployed using the Orbiter's remote manipulator arm. After release of the Spartan, pyrotechnics will be used to open the inflatable structure container, and the inflation sequence will follow. Figures 3 and 4 show details of the SSE in the stowed and on-orbit deployed configurations. The inflatable concentrator assembly consists of a thin Fresnel lens for focusing sunlight, a torus ring that supports the lens, and three struts that support the torus and attach to the Spartan spacecraft (Ref. 5).

The inflation subsystem will have the capability to pressurize the structure with gaseous nitrogen on- orbit and maintain the pressure within design limits. As shown in Fig. 5, the subsystem will consist of the gas supply, feed 
lines, valves, regulator, and instrumentation for monitoring pressure in the inflatable structure. The function of the regulator is to increase pressure as necessary, and a relief valve is used to release gas from the inflatable if the pressure exceeds design limits.

On-orbit conditions make it necessary to provide an inflation system that can vary the pressure. As the Spartan spacecraft and SSE move from orbital eclipse into orbital day, the temperature of the nitrogen gas in the torus and struts could show a large increase, and consequently the pressure could increase. The relief valve must prevent the pressure from increasing above $1.0 \mathrm{psi}$ to prevent possible leakage or failure of the inflatable. Conversely, as the vehicle moves from orbital day into darkness, the pressure could drop drastically. The regulator must insure that the pressure does not fall below 0.5 psi, the desirable operating pressure. The design pressure limits are driven by the strength of the various joints and seams in the inflatable torus and struts.

\section{Ground Tests for Development and Characterization of the Inflatable Structure}

A series of ground tests are being performed to evaluate the performance of inflatable prototype structures for the Shooting Star Experiment. Modal survey, thermal shock, thermal static deflection, and deployment tests are being done to allow development of verified structural models and verify operation of the inflatable system. In this paper, the focus is on modal vibration testing in atmosphere, vacuum, and thermal vacuum, and subsequent structural dynamic modeling and correlation with test.

\section{Modal Survey Testing in Atmospherlc Pressure}

Modal tests were performed for individual struts and a prototype concentrator assembly in a vibration lab at atmospheric pressure. It is realized that the air could have a considerable damping effect on the dynamics of the inflatable structures, and this was to be evaluated in later tests.

Figure 6 shows a single strut suspended vertically in the test configuration. Foam plugs were used at each end of the strut to seal it, and at the upper end to provide an opening for the pressure line. Soft supports were used to simulate a free-free condition, and shaker excitation was applied at the lower end of the strut. Testing was done at various pressures for two different thicknesses of the polyimide film material. It was found that the natural frequency varies as a function of both the film thickness and pressure inside the structure (Table 1). Data from this test was very valuable for determining the applicability of simple beam theory for modeling inflatable beam-like structures constructed of highly nonlinear materials. Measured mode shapes showed the general characteristics of a free-free beam. Dynamic modeling of a single strut and comparison to this test is described in a later section of the paper.

Next, testing was done for a prototype concentrator assembly consisting of a torus, lens simulator, and three tapered struts (Ref. 6). Figure 7 shows the test article suspended in a free-free configuration. The pressure line is visible at the top of the structure, and a tank of pressurized air can be seen in the background. Excitation was provided with a shaker attached to the support plate at the top of the inflatable assembly. It was determined during pretest investigations that excitation could not be applied directly to the surface of any of the inflatable components to obtain acceptable response. Modal tests werc run at three different inflation pressures, $0.25,0.50$, and $1.0 \mathrm{psig}$. As noted previously, $0.50 \mathrm{psi}$ is the desired on-orbit operating pressure.

During tests of the concentrator assembly, considerable leakage was observed, but it was concluded that the leak rate was slow enough to allow useful measurements. Considerable variation in the measured frequencies and mode shapes was observed for the three different pressures. Correlation of finite element models to the test data is currently in progress. It is yet to be determined if the nonlinear variation of material modulus properties is a critical factor for modeling of the inflatable assembly as it is for a single strut.

\section{Vacuum Testing of the Inflatable Structure and Pressurization system}

Testing of the inflatable is also being done in a vacuum chamber with four objectives: (1) obtain modal vibration characteristics in the absence of air, and compare to previous results in air, (2) visually evaluate packing schemes for folding the inflatable and placing it in the container, (3) evaluate the inflation sequence, starting from the packed configuration, and (4) characterize pressure regulators.

The modal survey test will be done for a range of pressures, including the 0.5 psi operating condition, and all modes of interest below $100 \mathrm{~Hz}$ will be measured. A laser vibrometer will be placed outside the vacuum chamber for obtaining measurements, and electrodynamic shakers will be mounted inside the chamber.

Simulation of the inflation sequence is difficult in one particular area: reducing the effects of gravity such that onorbit microgravity conditions are matched as closely as possible. The test configuration in vacuum will have the inflatable container mounted at the top of the chamber with its doors pointed toward the bottom of the chamber. A mechanism must be designed to prevent the inflatable from falling out of the container when the inflation sequence begins.

In preparation work for the vacuum testing, an investigation of the leak rate for the inflated concentrator was done. Initially, after the structure was placed in the vacuum chamber and inflated with nitrogen, a high leak rate of $0.6 \mathrm{psi} / \mathrm{hr}$ was detected. Next, the concentrator was inflated with helium, and a "sniffer" device was used to locate leaks. Kapton polyimide tape was utilized to repair the structure, with the result that the leak rate was reduced to $.07 \mathrm{psi} / \mathrm{hr}$.

As the second stage of preparatory work, the vacuum was drawn and the pressure in the concentrator assembly was monitored. The initial inflation pressure for the structure was $0.5 \mathrm{psig}$ (15.2 psia), and it was found that the concentrator pressure followed the chamber pressure down to reach a final pressure of 0.5 psia. That is, during the pumpdown of the chamber (reduction to 0 psia), the pressure inside the inflatable maintained $0.5 \mathrm{psi}$ relative to the external pressure. This was a significant test with very 
encouraging results in regard to on-orbit conditions and operability of the structure. The pressure inside the inflatable was manually increased as the chamber was brought back to atmospheric pressure.

\section{Testing In Thermal Vacuum}

In addition to modal vibration tests described previously for atmospheric pressure and vacuum conditions, testing will also be done in a thermal vacuum chamber. The combined database will allow development of structural dynamic models that take into account the variation of the inflatable vibration properties due to temperature, frequency, and external pressure changes.

Thermal vacuum testing will also be done to simulate the orbital transition from eclipse to sunlight (and from sunlight to darkness) to determine the response of the structure to thermal shock and the static deflection due to the temperature gradient. It must be assured that the SSE can maintain pointing accuracy during thermally induced deflections and vibrations on-orbit.

\section{Structural Dynamic Medeling of the Inflatable Structure and Correlation with Test}

As stated in the description of single strut modal testing, the measured data provided a means of determining if simple beam theory can be used in modeling. Using results described in Ref. 7 and the Bernoulli-Euler equation for beam vibrations, a nonlinear function of elastic modulus (Fig. 8) was determined that provided an accurate simple beam model. These results, and the findings of Main (Ref. 7) are very significant in showing that linear finite element analysis can be useful in modeling of inflatable structures. Verified mathematical models of the concentrator assembly will be used in on-orbit dynamic simulations for control system design.

\section{Summary}

The Shooting Star Experiment (SSE) is a Shuttle payload and technology demonstrator flight for solar thermal propulsion, a concept for producing thrust sufficient for orbital transfers, and utilizing innovative, lightweight structures. This paper has presented a description of the SSE's inflatable concentrator that consists of a torus, Fresnel lens, and three struts for mounting the inflatable to a Spartan spacecraft. A comprehensive ground test program was discussed for development and verification of the solar concentrator assembly, and for providing a complete database for structural modeling. Dynamic models of single struts demonstrated the use of linear Bernoulli-Euler beam theory for predicting modal characteristics of beamlike inflatable structures constructed of nonlinear materials.

\section{Acknowledgments}

Larry Bradfond of United Applied Technologies, Inc., has done innovative work in design and development of the inflatable concentrator assembly for SSE using polyimide film materials. John Lassiter of the Dynamics Test Branch at Marshall Space Flight Center (MSFC) is acknowledged for his work in providing modal and frequency response test data used in this study. Drew Smith and Greg Schunk, both of MSFC, have done extensive work in test planning and coordination for the vacuum and thermal vacuum tests, respectively.

\section{References}

1. Stewart, Jesse F., and Martin, James A.,"Dual Fuel Solar Thermal Stage: Ideal Analysis", Journal of Spacecraft and Rockets, Vol. 33, No. 5, 1996, pp. 752754.

2. Patel, S., and Emrich, W. J., Jr., "Solar Thermal Upper Stage (STUS) Feasibility Study", Proceedings of ASME/JSME/JSES_International Solar Energy Conference, Maui, HI, March 1995.

3. Lyles, Garry M., "NASA Solar Thermal Propulsion Project", Solar Thermal Propulsion Workshop Proceedings, NASA Marshall Space Flight Center, Huntsville, AL March 19-20, 1997.

4. Freeland, Robert E., "Inflatable Antenna Flight Experiment Experiences", Solar Thermal Propulsion Workshop Proceedings, NASA Marshall Space Flight Center, Huntsville, AL March 19-20, 1997.

5. Shooting Star Experiment (SSE) Requirements. Verification and Compliance Document, MSFC-RQMT2630, July 1997.

6. Lassiter, John, "Shooting Star Experiment Prototype Inflatable Strut/Torus Assembly Modal Survey", ED73(97-69), NASA Marshall Space Flight Center, Huntsville, AL, June 1997.

7. Main, John A., Carlin, Robert A., Garcia, Ephrahim, Peterson, Steven W., and Strauss, Alvin M., "Dynamic Analysis of Space-Based Inflated Beam Structures", Journal of the Acoustical Society of America, Vol. 97, No. 2, Feb. 1995, pp. 1035-1045.

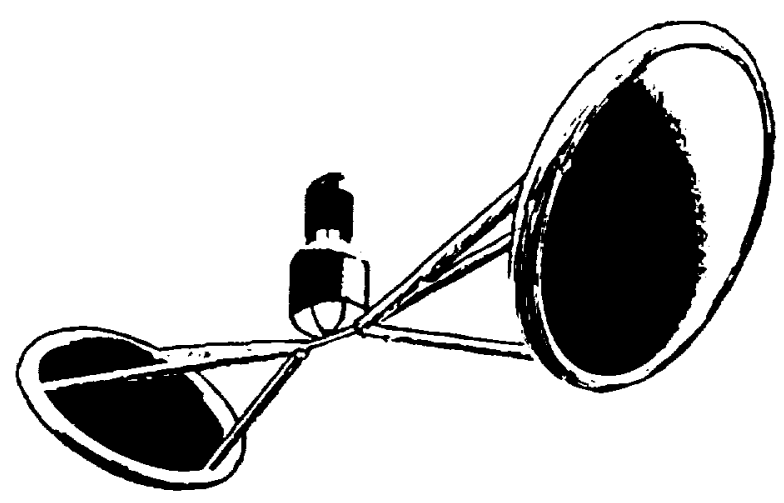

Figure 1. Solar Thermal Upper Stage 

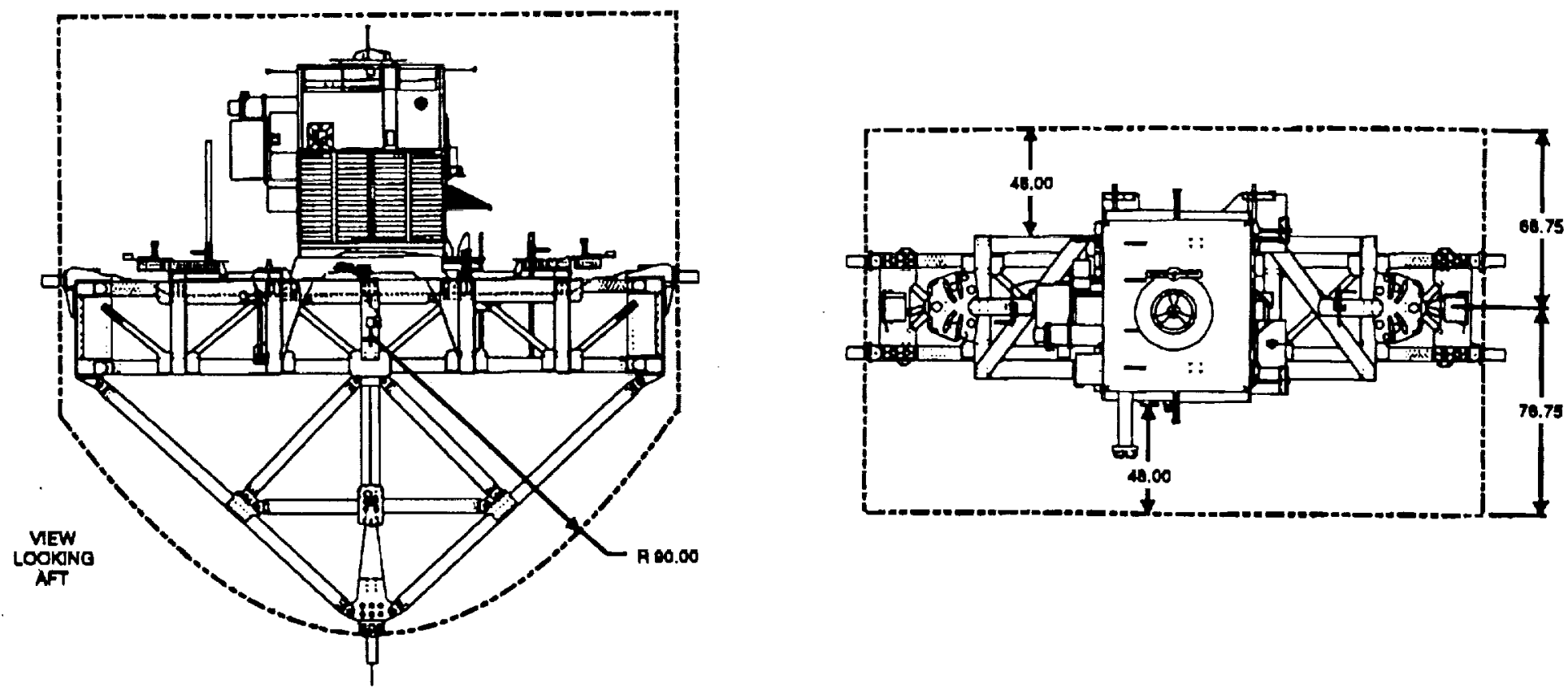

Figure 2. Payload Envelope for Spartan Spacecraft and Carrler In Shuttle Orbiter

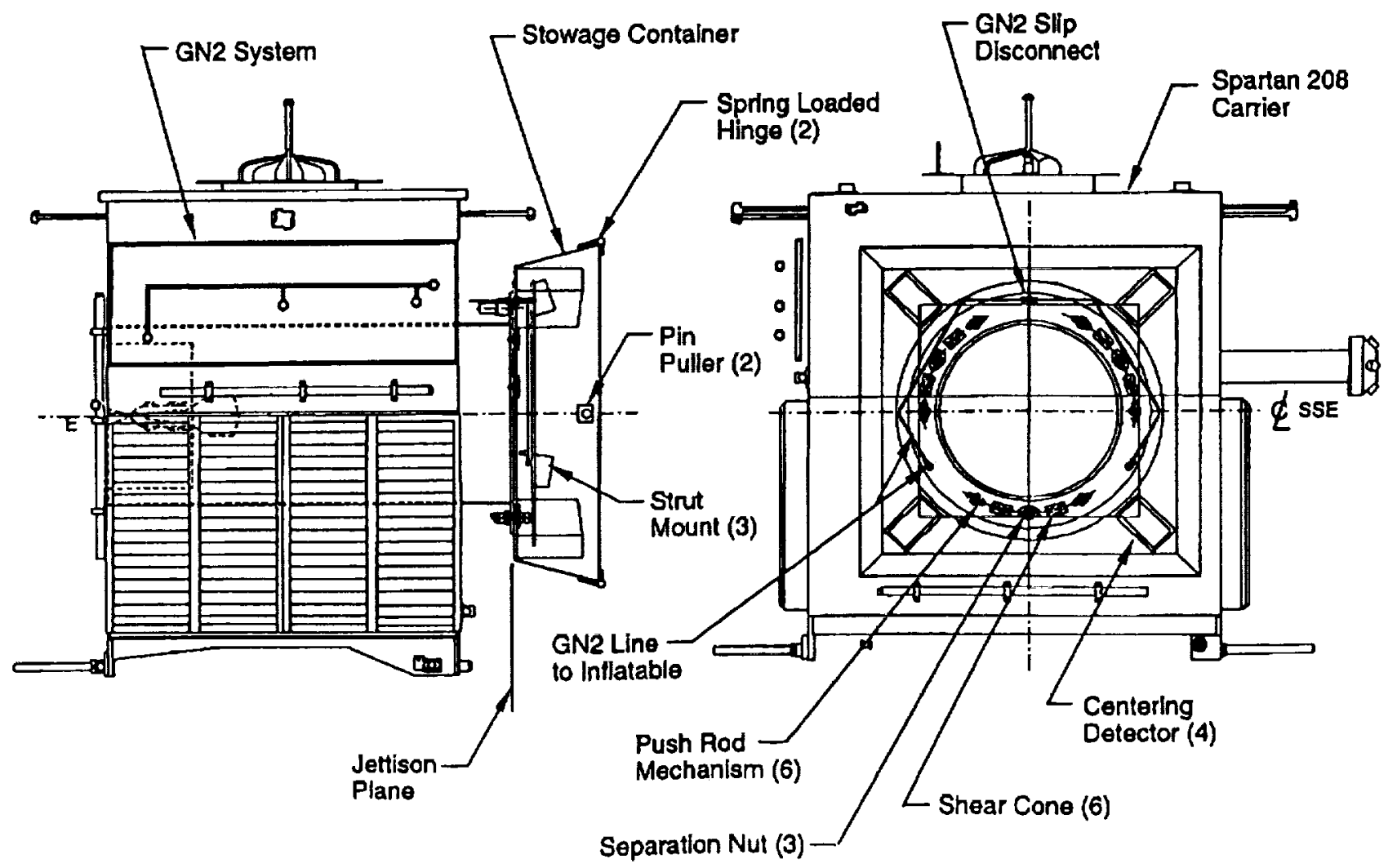

Figure 3. Shooting Star Experiment (SSE) In Stowed Configuration 


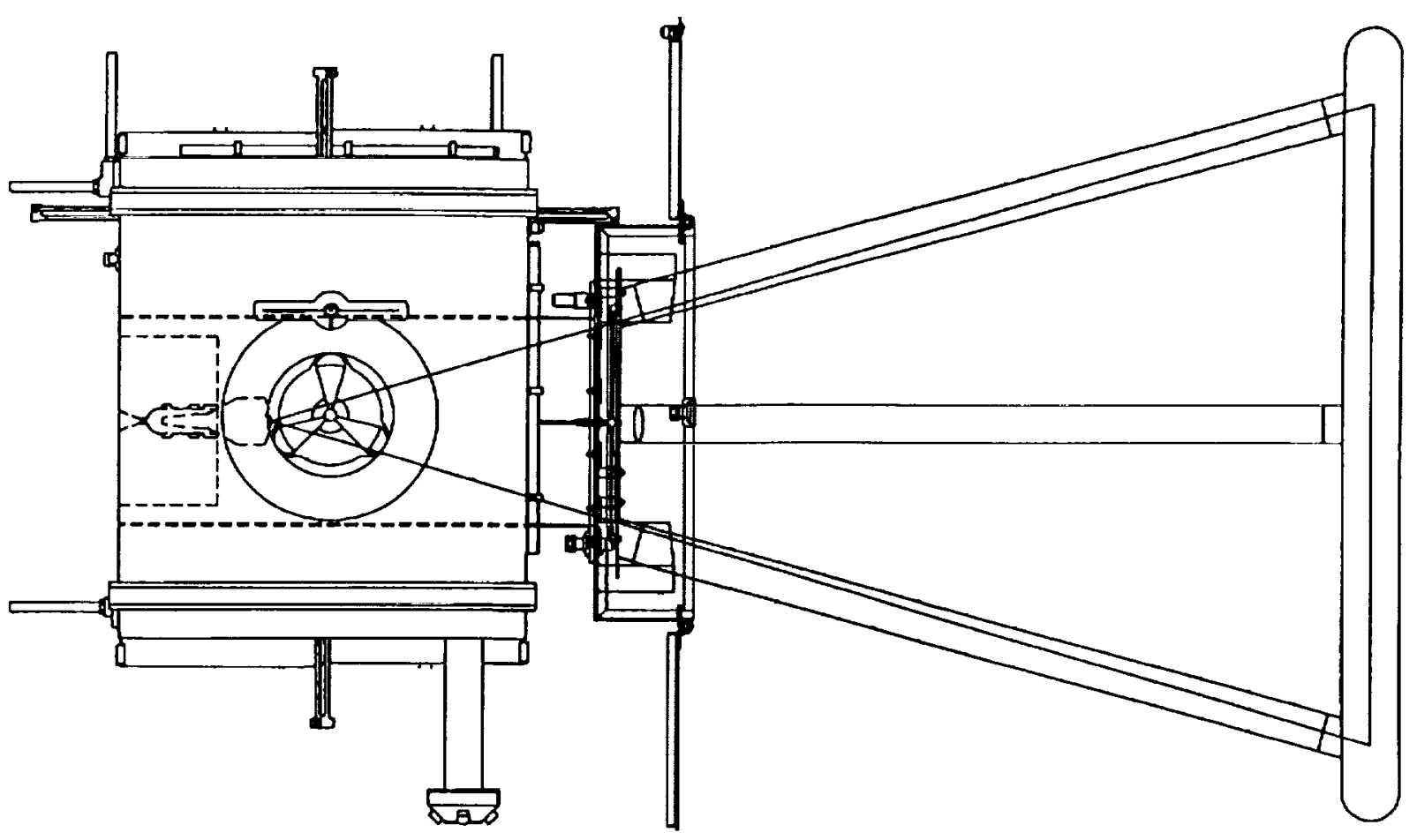

Figure 4. On-Orbit Deployed Configuration for SSE and Spartan Spacecraft

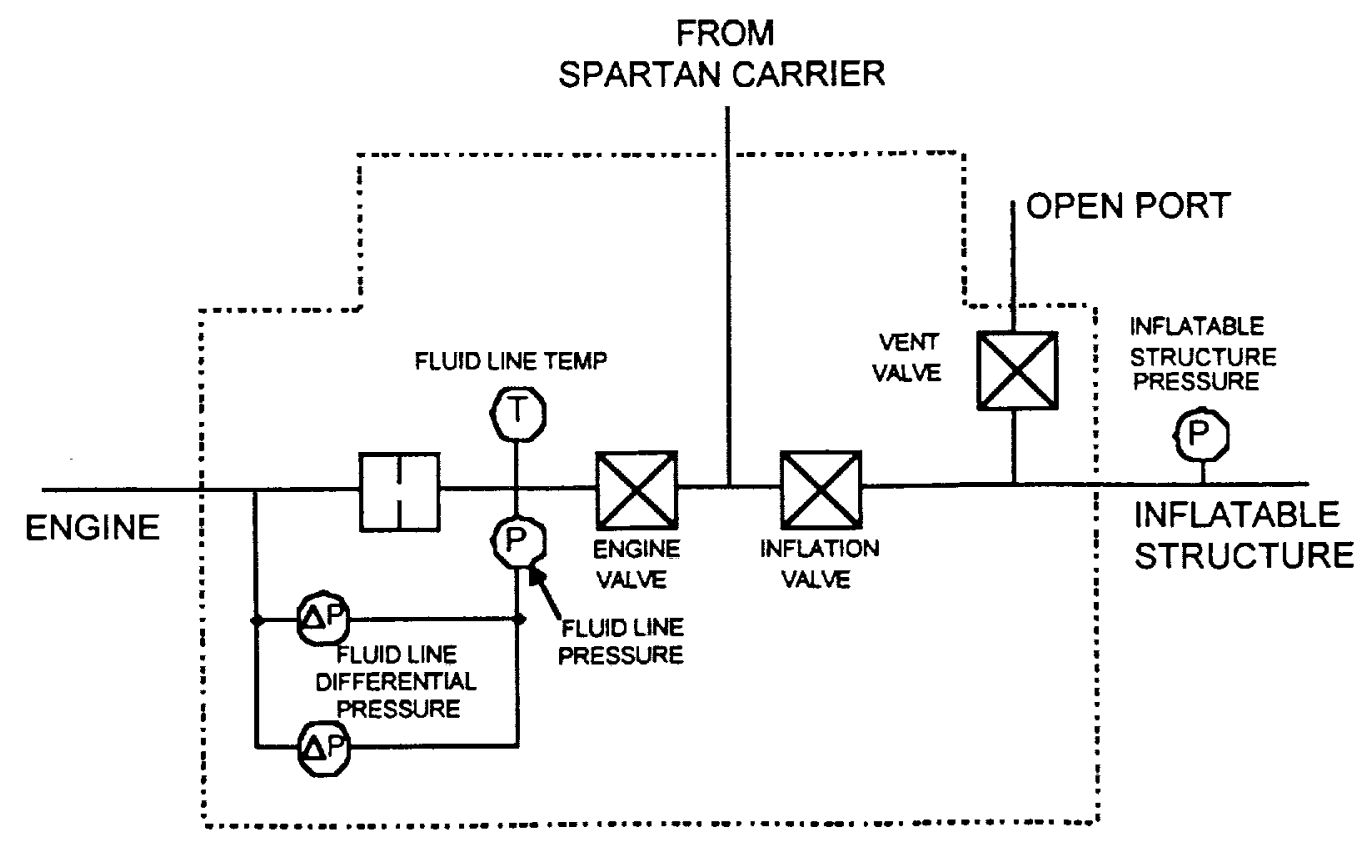

Figure 5. Fluid System and Inflation Subsystem for Spartan/SSE

American Institute of Aeronautics and Astronautics 


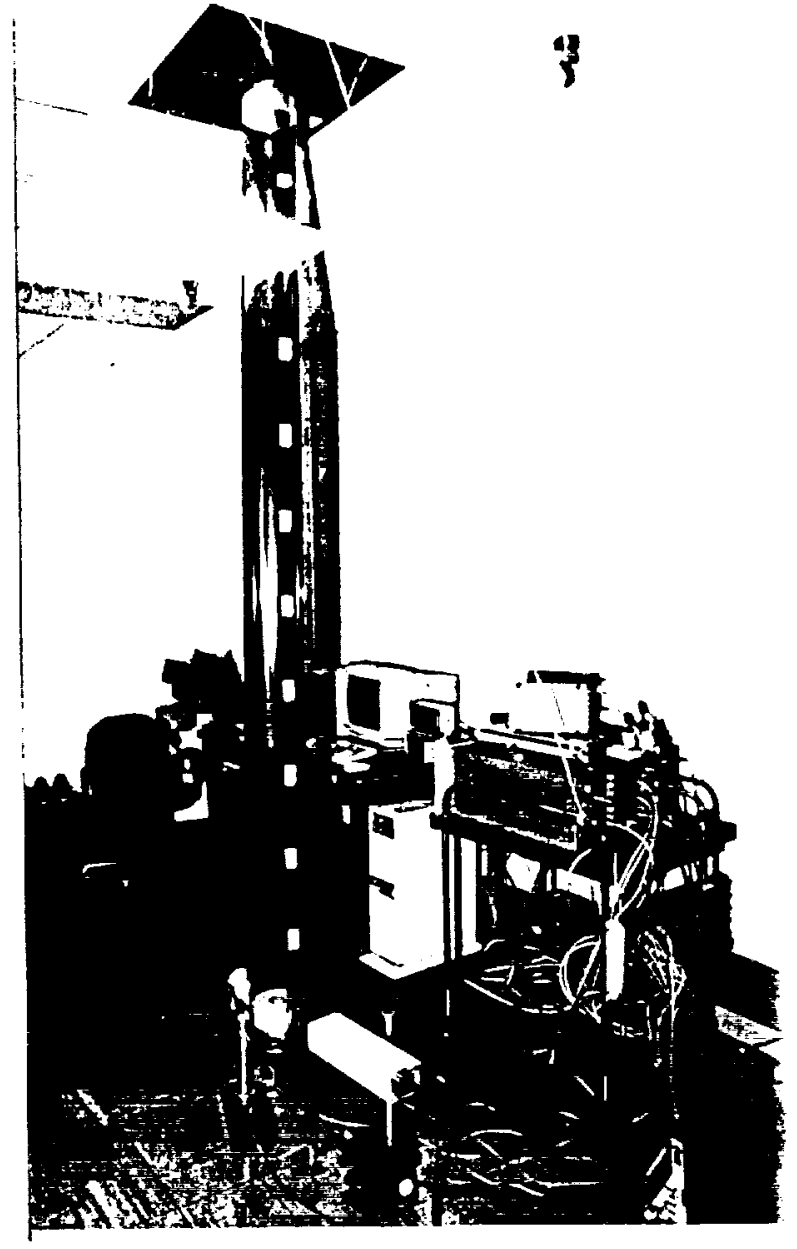

Figure 6. Inflated Strut In Modal Test Configuration

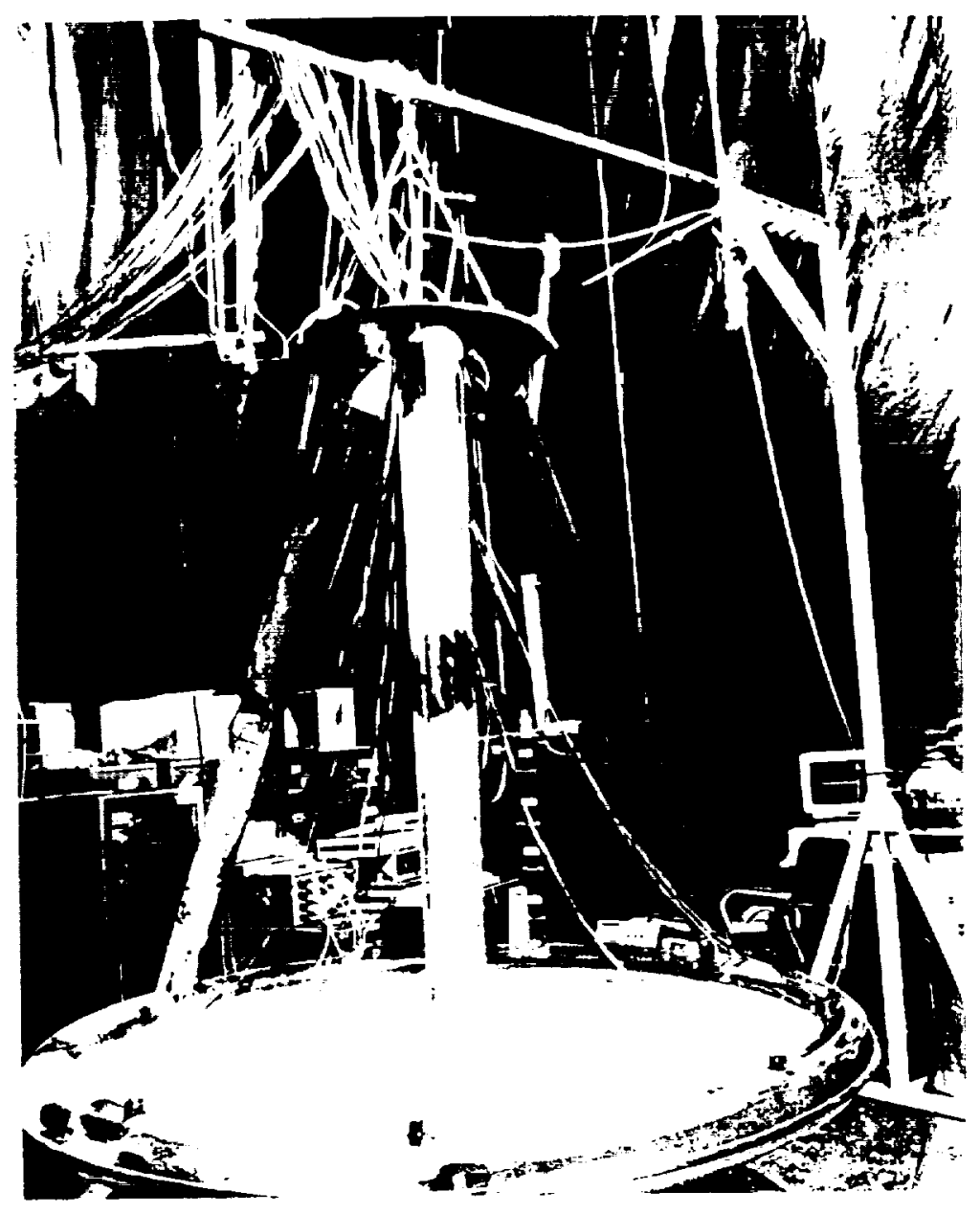

Figure 7. Inflatable Concentrator Assembly Modal Survey Test

Table 1. Inflated Strut Frequencies for Various

Pressures and Polyimide Film Thicknesses

\begin{tabular}{llll}
\hline & & & \\
\hline $\begin{array}{l}\text { Film } \\
\text { Thickness } \\
\text { (in) }\end{array}$ & $\begin{array}{l}\text { Pressure } \\
\text { (psi) }\end{array}$ & $\begin{array}{l}\text { First } \\
\text { Freq. }\end{array}$ & $\begin{array}{l}\text { Second } \\
\text { Freq. }\end{array}$ \\
\hline \multirow{2}{*}{0.002} & 0.76 & 24.31 & 71.84 \\
& 1.40 & 24.60 & 71.38 \\
0.003 & 1.00 & 24.27 & 73.25 \\
& 1.34 & 24.60 & 73.52 \\
\hline
\end{tabular}




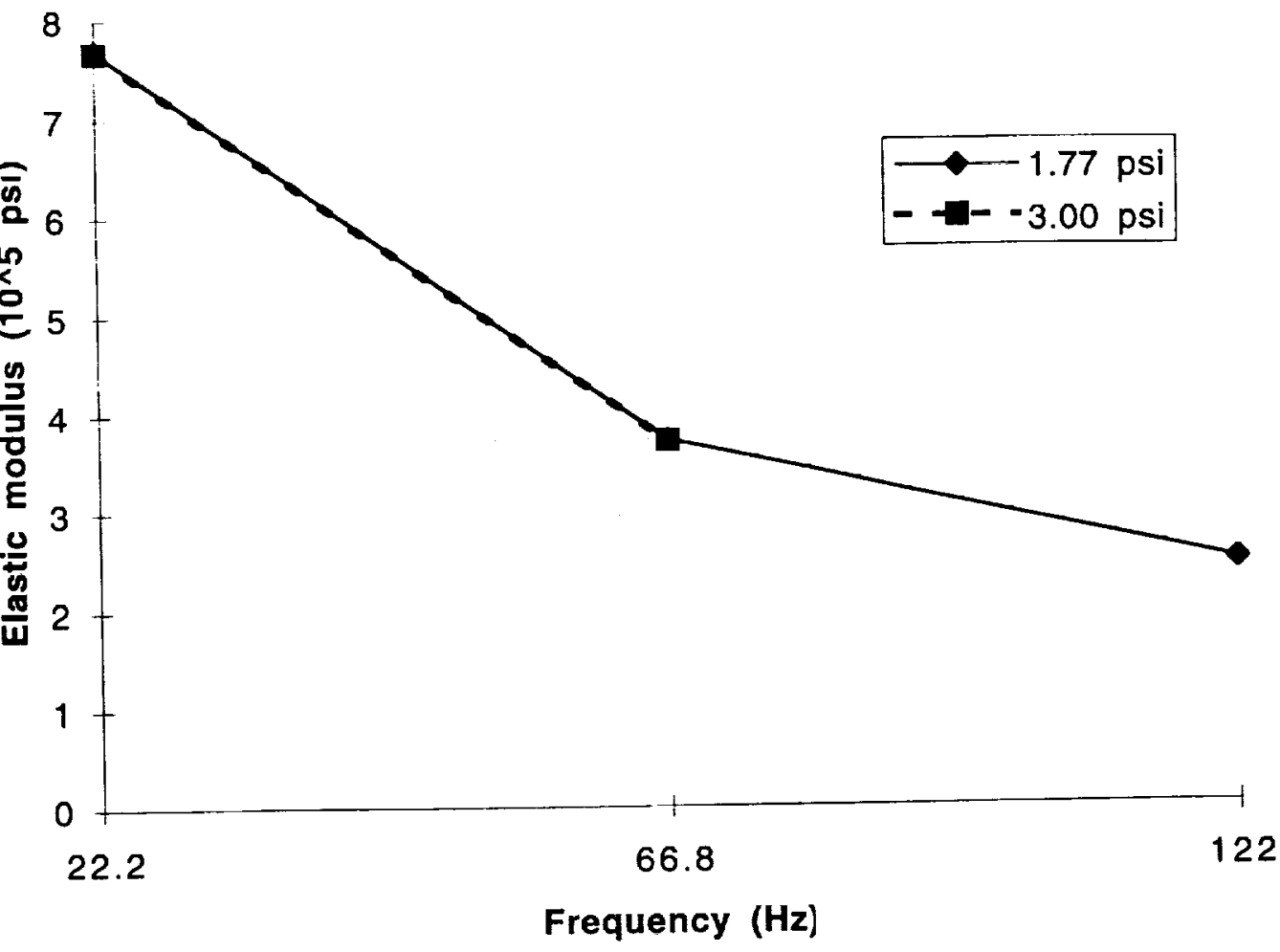

Figure 8. Inflated Strut Elastic Modulus as Function of Frequency and Material Thickness 